\title{
Diagnostic Application of Multirow Computed Tomography of the Hip Joint of Japanese Quails \\ (Coturnix Japonica)
}

\section{mAuthor(s)}

Paśko S'
Bartyzel BJ"
Dzierzęcka M"
Murawska D"II
Szlufik K"
Bakoń L"
Gruszczyńska Jv
Grzegrzółka Bv
Nowicki M ${ }^{v 1}$

Virtual Reality Techniques Division, Institute of Micromechanics and Photonics, Faculty of Mechatronics, Warsaw University of Technology, Św. A. Boboli 8, 02-525 Warszawa, Poland

" Department of Morphological Sciences, Faculty of Veterinary Medicine, Nowoursynowska 159, 02-776 Warszawa, Warsaw University of Life Sciences - SGGW, Poland

III Department of Commodity Science and Animal Improvement, Faculty of Animal Bioengineering, Oczapowskiego 5, 10-719 Olsztyn, University of Warmia and Mazury in Olsztyn, Poland

iv Department of Clinical Radiology, Medical University of Warsaw, Banacha 1a, 02-097 Warszawa, Poland

$\checkmark$ Department of Genetics and Animal Breeding, Faculty of Animal Sciences, Ciszewskiego 8, 02-786 Warszawa, Warsaw University of Life Sciences - SGGW, Poland

vi Department of Food Hygiene and Public Health Protection, Faculty of Veterinary Medicine, Nowoursynowska 159, 02-776 Warszawa, Warsaw University of Life Sciences - SGGW, Poland

\section{aMail Address}

Corresponding author e-mail address Dr. Sławomir Paśko

Virtual Reality Techniques Division, Institute of Micromechanics and Photonics, Faculty of Mechatronics, Warsaw University of Technology, Św. A. Boboli 8, 02-525 Warsaw, Poland

Tel: $\quad$ (48) 222348442

Email: s.pasko@mchtr.pw.edu.pl

\section{EKeywords}

Computed tomography, hip joint, Japanese quail.

\section{ABSTRACT}

The morphological assessment of selected parts of the hindlimb of Japanese quails (Temminck \& Schlegel, 1849), with particular emphasis on hip joint structures, was performed, using a 128-row scanner (GE Optima Aquilion, Toshiba, Japan). Eight dead 3-month-old Japanese quails were evaluated. During intravital examination of those birds, no hindlimb abnormalities or locomotion disorders were detected. Bird body, which hip joints and other structures of hindlimbs were studied, was examined in posterioranterior position. The following hip joint structures, on both sides, were assessed in this study: hip joint gap width, acetabulum width, femoral head diameter, and femoral shaft width. The applied imaging method allowed accurate assessment of the selected structures. There was low variability between left and right hindlimbs and among individuals. Modern imaging techniques, such as multirow computed tomography (MCT) allows quick intravital assessment of normal and pathological structures of poultry bones and joints.

\section{INTRODUCTION}

Diagnostic imaging is more frequently used for the detection of pathologies related to the passive part of the locomotor system in poultry (Charuta et al. , 2011; Charuta et al., 2012). Modern techniques, such as magnetic resonance imaging (MRI) or multirow computed tomography (MCT), allow quick intravital assessment of specific body structures, including bones and joints. Diagnostic imaging is a rapidly developing field in human and veterinary medicines (Chang et al., 2014;, Aguado et al., 2015). It is also used for scientific research on the growth and development of organisms (Li et al., 2015), as well as on different species of poultry (Andrássy-Baka et al., 2003; Locsmándi et al., 2004; Romvári et al., 2004). Multirow computed tomography scanners (MCT) and magnetic resonance imaging (MRI) have been significantly improved, and today enable the diagnosis of various types of diseases. The influence of these diseases on locomotion disorders of poultry have been studied using optical 3D techniques (Caplen et al., 2012).

The Japanese quail has been used as animal model in many areas of developmental biology studies. Some authors suggest the possibility of using this model also in research on human aging and diseases (Huss et al., 2008). The assumption of this study is that MCT could be used as a method to diagnose abnormalities in the hip joint structures of Japanese quails, and to examine the joints of other species of breeding poultry. The early, intravital diagnosis of pathologies allows selecting individuals with good genetic potential for breeding. The aims of this study were to perform the examination and morphological evaluation of hip joints of Japanese quails using advanced imaging techniques. 
Paśko S, Bartyzel BJ, Dzierzęcka M, Murawska D, Szlufik K, Bakoń L, Gruszczyńska J, Grzegrzółka B,

Nowicki MV

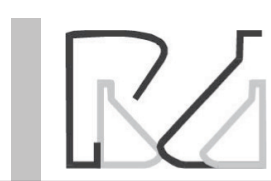

Closer examination of the animal gives a more accurate diagnosis, and therefore, allow for more accurate treatments. Previously detected changes in individual subjects may prevent them in other animals, consequently shortening suffering and recovery times.

\section{MATERIAL AND METHODS}

Eight (five males and three females) dead 3-monthsold Japanese quails were studied. The birds selected for post mortem examination were culls of the flock of the Department of Genetics and Animal Breeding, Faculty of Animal Sciences, Warsaw University of Life Sciences (SGGW), Poland. Birds were reared according to the conditions recommended for this species, and fed ad libitum a diet containing $2600 \mathrm{kcal}$ energy and $21.5 \%$ crude protein. Preliminary clinical examination of those birds and their locomotor system did not reveal any abnormalities.

Imaging examination was performed using a 128row MCT scanner (GE Optima Aquilion, Toshiba, Japan). Birds were placed in posterioranterior position in sealed airtight containers. Scanning parameters were: voltage of $120 \mathrm{kV}$, time of exposure of $1.5 \mathrm{~s}$, exposure of $7 \mathrm{mAs}$, current of $150 \mathrm{~mA}$, and slice thickness of 0.63.

Pixel size in subsequent image sequences was dependent on the size of the measured object. Therefore, pixel size was equal to $0.15 \mathrm{~mm}$ for the smallest object and $0.20 \mathrm{~mm}$ for the largest. It was decided to dispense with a fixed pixel size to fully exploit the field of the matrix recording, which size was $512 \times 512$ pixels. After the MCT images were obtained, the hindlimb was described with particular emphasis on the hip joint.

The VolView3 software was used to perform the following measurements on both hindlimbs ( $L$ and $R$ ): acetabulum width (AW), hip joint gap width (JGW), femoral head diameter together with trochanter (FS), and femoral shaft width (FW), as shown in Figure 1.

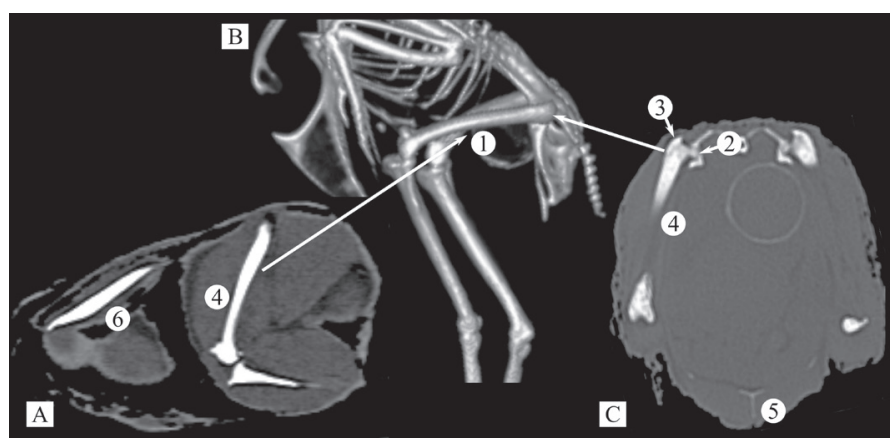

Figure 1 - Imaging diagnostic of Japanese quail A) posterioranterior position B) volumetric reconstruction C) cross-section (1 - left femur, 2 - femoral head, 3 - trochanter major, 4 - femoral shaft, 5 - sternum, 6 - humerus)
Diagnostic Application of Multirow Computed Tomography of the Hip Joint of Japanese Quails (Coturnix Japonica)

Statistical analysis of the evaluated hip joint parameters was performed using the software IBM SPSS Statistics 21.0. The obtained values were statistically described. Data were analysed for normality by Kolmogorow-Smirnov test, with Lilliefors modification. Pearson's correlation analysis was performed for specific characteristics of the analysed parameters.

\section{RESULTS}

Results of this study show a slight, although not statistically significant, variation of analysed characteristics between left and right hindlimbs, as well as between individuals (Table 1). Difference between AW values (average of $0.07 \mathrm{~mm}$ ), may be the result of error caused by inaccuracy in limbs arrangement and subsequently differences in their exposure on MCT images. The standard deviation of AW was $\pm 0.18 \mathrm{~mm}$. The largest standard deviation was $0.50 \mathrm{~mm}$, recorded for right femoral shaft width (FWR) in females, which average was equal to $3.7 \mathrm{~mm}$. A slight, but not statistically significant standard deviation $(0.05 \mathrm{~mm})$ was observed in the length of the femoral head on the left leg in males.

The average standard deviation value of most measurements is close to the average pixel size of the tomographic image. Therefore, it is expected that decreasing pixel size will reduce the average standard deviation of the obtained results.

Among the evaluated parameters, only FSR ( $p=$ $0.001)$ did not present normal distribution.

Pearson's correlation coefficients calculated for selected hip joint parameters are shown in Table 2. A statistically significant correlation of $0.707(p=0.05)$ was observed only between JGWR and JGWL. In addition, despite not statistically significant $(p=0.07)$, a clear correlation was observed between acetabulum and hip joint gap width on the left hindlimb.

\section{DISCUSSION}

Proper formation of the skeleton in domestic poultry is essential for production and breeding. Therefore, extensive research on the quality of the skeleton has been carried out, particularly on skeletal problems in the hindlimb, which supports the weight of the whole body (Fan et al., 2011; Charuta et al., 2013). In order to function normally, the anatomical structure of the limbs of breeding birds needs to be correct. However, in intensive livestock production, limb deformation and sometimes even fractures are recorded (Cooper et al., 2008). Reilly (2000), analyzed the involvement of particular sections 
Table 1 - Mean and standard deviation (SD) for each trait of hip and knee joints in Japanese quails.

\begin{tabular}{lccccccccc}
\hline \multirow{2}{*}{ Trait } & \multicolumn{3}{c}{ All birds } & & \multicolumn{3}{c}{ Males } & \multicolumn{3}{c}{ Females } \\
\cline { 2 - 10 } & $\mathrm{N}$ & Mean & SD & N & Mean & SD & N & Mean & SD \\
\hline AWL & 8 & 1.01 & 0.18 & 5 & 0.92 & 0.15 & 3 & 1.17 & 0.12 \\
AWR & 8 & 0.94 & 0.18 & 5 & 0.92 & 0.19 & 3 & 0.97 & 0.21 \\
\hline JGWL & 8 & 0.83 & 0.14 & 5 & 0.80 & 0.14 & 3 & 0.87 & 0.15 \\
JGWR & 8 & 0.80 & 0.13 & 5 & 0.80 & 0.12 & 3 & 0.80 & 0.17 \\
\hline FWL & 8 & 3.78 & 0.15 & 5 & 3.78 & 0.18 & 3 & 3.77 & 0.12 \\
FWR & 8 & 3.84 & 0.32 & 5 & 3.92 & 0.16 & 3 & 3.70 & 0.50 \\
\hline FSL & 8 & 5.95 & 0.09 & 5 & 5.96 & 0.05 & 3 & 5.93 & 0.15 \\
FSR & 8 & 6.00 & 0.11 & 5 & 5.96 & 0.09 & 3 & 6.07 & 0.12 \\
\hline
\end{tabular}

Hindlimb width of acetabulum (AWLIAWR), width of hip joint gap (JGWLVGWR), femoral shaft width (FWLIFWR) and femoral head diameter together with trochanter (FSLLFSR), left $(L)$, right $(R), \quad N$ - number of objects.

of the lower limbs in the locomotion of Japanese quails, but did not provide a detailed morphological analysis of the joints. Abourachid et al. (2011) used 3D technology to analyze locomotion in quails. In scientific publications, there is no information on the diagnosis of the pathology of the hindlimb joints of quails. It seems that undertaking such research would be a valuable contribution for the knowledge in this field.

The current breeding, rearing and genetic selection practices of poultry are aimed at increasing growth rate. The progeny of poultry with excellent production parameters in breeding programs often present health and skeletal problems, including diseases of the joints, which etiology is rarely elucidated. High body weight and growth imbalance between the muscle mass and bones can cause deformities and fractures in poultry (Burs et al., 2008). The function of the hip joint and related diseases are well established in humans (Turmezei et al., 2014; Vahdati et al., 2014). Reduction of the hip joint gap may be the first symptom of osteoarthritis in this joint. The hip joint gap narrows when the cartilage that separates the soft tissues and bones of the joint degenerates. In humans, the knee and hip are the sites most often affected by osteoarthritis, and this disease is more frequent in women (Roemer et al., 2014).

Genetic factors, in addition to environmental factors, have a significant influence on the development of articular diseases. It should be noted that the selection for meat production within breeds and lines of mainly chickens and turkeys, but also of quails, has led to rapid growth and deposition of muscle tissue in the body, weight gain and high dressing percentage (Resende et al., 2005; Murawska, 2013). Despite the indubitable achievements in production performance, there were also negative consequences of the selection for weight gain, such the increasing incidence of metabolic disorders and diseases of the skeletal system (Ahmed \& Soliman, 2013, Charuta et al., 2013). The so-called "weak legs", manifested by defective bones structure or dyschondroplasia, are examples of the "inadequacy" of the poultry's body to fast growth rates (Leeson \& Summers, 1988; Ferket \& Sell, 1989; Leach \& Lilburn, 1992; Havenstein et al., 1994).

Table 2 - Pearson's correlations between each measured traits for all Japanese quails.

\begin{tabular}{|c|c|c|c|c|c|c|c|c|}
\hline Trait & & AWR & JGWL & JGWR & FWL & FWR & FSL & FSR \\
\hline \multirow[t]{2}{*}{ AWL } & $r$ & -0.016 & 0.669 & 0.362 & -0.465 & -0.435 & 0.043 & 0.000 \\
\hline & $p$ & 0.970 & 0.070 & 0.378 & 0.246 & 0.282 & 0.920 & 1.000 \\
\hline \multirow[t]{2}{*}{ AWR } & $r$ & & 0.292 & -0.059 & 0.611 & 0.462 & -0.460 & 0.579 \\
\hline & $p$ & & 0.482 & 0.889 & 0.108 & 0.249 & 0.252 & 0.133 \\
\hline \multirow[t]{2}{*}{ JGWL } & $r$ & & & 0.629 & -0.104 & -0.024 & 0.222 & 0.192 \\
\hline & $p$ & & & 0.095 & 0.807 & 0.954 & 0.597 & 0.648 \\
\hline \multirow[t]{2}{*}{ JGWR } & $r$ & & & & 0.147 & -0.035 & 0.707 & -0.204 \\
\hline & $p$ & & & & 0.729 & 0.935 & 0.050 & 0.628 \\
\hline \multirow[t]{2}{*}{ FWL } & $r$ & & & & & 0.539 & -0.104 & 0.539 \\
\hline & $p$ & & & & & 0.168 & 0.807 & 0.168 \\
\hline \multirow[t]{2}{*}{ FWR } & $r$ & & & & & & -0.171 & 0.254 \\
\hline & $p$ & & & & & & 0.686 & 0.544 \\
\hline \multirow{2}{*}{ FSL } & $r$ & & & & & & & -0.289 \\
\hline & $p$ & & & & & & & 0.488 \\
\hline
\end{tabular}

Hindlimb width of acetabulum (AWLIAWR), width of hip joint gap (JGWLIGWR), femoral shaft width (FWLIFWR) and femoral head diameter together with trochanter (FSLIFSR), left $(\mathrm{L})$, right (R), r - Pearson's correlation (two sided); $p$ - probability. 
Paśko S, Bartyzel BJ, Dzierzęcka M,

Murawska D, Szlufik K, Bakoń L, Gruszczyńska J, Grzegrzółka B,

Nowicki MV

\section{Diagnostic Application of Multirow Computed Tomography of the Hip Joint of Japanese Quails (Coturnix Japonica)}

Only the birds in the flock with high genetic potential and resistance to diseases should be selected for reproduction. The examination of the hip joint gap after slaughter is not the best solution because it equally eliminates from the flock healthy and sick animals. Imaging diagnosis is a better solution because it allows to observe any changes in live animals, and do not require their sacrifice.

In humans, extensive studies conducted by a team led by Lequesne et al. (2004) showed the importance of the function played by the above-mentioned hip joint gap. Diseases of this joint were described in the publications of Goker et al. (2003), Daysal et al. (2007), and Sipola et al. (2011). Research on human diseases are the most advanced, and directly indicate the need for the for research on articular diseases in animals.

Multirow computed tomography (MCT) is a very good diagnostic tool for assessing the health of farmed poultry. Studies using this technology can serve as a model, and may be applied to assess the health status of other poultry species.

\section{ACKNOWLEDGEMENTS}

We wish to thank Dr. F. Rzepiński, Dr. M. Mikuła and Dr. J. Bonecka for their contribution for this article.

\section{REFERENCES}

Abourachid A, Hackert R, Herbin M, Libourel PA, Lambert F, Gioanni H, et al. Bird terrestrial locomotion as revealed by $3 D$ kinematics. Zoology 2011;114(6):360-368.

Aguado E, Pascaretti-Grizon F, Goyenvalle E, Audran M, Chappard D. Bone mass and bone quality are altered by hypoactivity in the chicken. PLoS One 2015;10(1):e0116763.

Ahmed YA, Soliman SA. Long bone development in the Japanese quail (Coturnix coturnix japonica) embryos. Pakistan Journal of Biological Sciences 2013;16(18):911-919.

Andrássy-Baka G, Romvári R, Sütő Z, Csapó J, Szabó A, Locsmándi L. The study of the broiler chickens' growth by X-ray computerized tomography. Acta Agraria Kaposváriensis 2003;2:19-29.

Burs M, Zdybel A, Faruga A, Laskowski J. Effect of housing conditions on the mechanical strength of the femur and tibia in turkey. Medycyna Weterynaryjna 2008;64:202-206.

Caplen G, Hothersall B, Murrell JC, Nicol CJ, Waterman-Pearson AE, Weeks CA, Colborne GR. Kinematic. Analysis Quantifies Gait Abnormalities Associated with Lameness in Broiler Chickens and Identifies Evolutionary Gait Differences. PLoS One 2012;7(7):e40800.

Chang G, Deniz CM, Honig S, Egol K, Regatte RR, Zhu Y, et al. MRI of the hip at 7 tesla: feasibility of bone microarchitecture, high-resolution cartilage, and clinical imaging. Journal of Magnetic Resonance Imaging 2014;39(6):1384-1393.

Charuta A, Cooper RG, Pierzchała M, Horbańczuk JO. Computed tomographic analysis of tibio-tarsal bone mineral density and content in postnatal turkey (Meleagris gallopavo) as influenced by age and sex. Czech Journal of Animal Science 2012;57:572-578.

Charuta A, Dzierzęcka M, Komosa M, Biesiada- Drzazga B, DziałaSzczepańczyk E, Cooper RG. Age- and sex-related changes in mineral density and mineral content of the tibiotarsal bone in quails during post-hatching development. Kafkas Üniversitesi Veteriner Fakültesi Dergisi 2013;19:31-36.

Charuta A, Dzierzęcka M, Majchrzak T, Czerwiński E, Cooper RG. Computergenerated radiological imagery of the structure of the spongious substance in the postnatal development of the tibio-tarsal bones of the Peking domestic duck (Anas platyrhynchos var. domestica). Poultry Science 2011;90:830-835.

Cooper RG, Naranowicz H, Maliszewska E, Tennett A, Horbańczuk JO Sex-based comparison of limb segmentation in healthy and tibiotarsal rotation ostriches aged 14 months. Journal of the South African Veterinary Association 2008;79:142-144.

Daysal GA, Goker B, Gonen E, Demirag MD, Haznedaroglu S, Ozturk MA et al. The relationship between hip joint space width, center edge angle and acetabular depth. Osteoarthritis and Cartilage 2007;15(12):14461451.

Fan M, Peng J, Wang A, Zhang L, Liu B, Ren Z, et al. Emu model of fullrange femoral head osteonecrosis induced focally by an alternating freezing and heating insult. Journal of International Medical Research 2011;39(1):187-198.

Ferket PR, Sell JL. Effect of severity of early protein restriction on Large Turkey toms. 1. Performance characteristics and leg weakness. Poultry Science 1989;68:676-686.

Goker B, Sancak A, Arac M, Shott S, Block JA. The radiographic joint space width in clinically normal hips: effects of age, gender and physical parameters. Osteoarthritis and Cartilage 2003;11(5):328-334.

Havenstein GB, Ferket PR, Scheideler SE, Larson BD. Growth, livability, and feed conversion of 1957 vs. 1991 broilers when fed „typical” 1957 and 1991 broiler diets. Poultry Science 1994;73(12):1785-1794.

Huss D, Poynter G, Lansford R. Japanese quail (Coturnix japonica) as a laboratory animal model. Lab Animal 2008;37(11):513-519.

Leach $R$, Lilburn $M$. Current klownedge on the etiology of tibial dyschondroplasiain the avian species. Poultry Science 1992;4:57-65.

Leeson S, Summers JD. Some nutritional implications of leg problems with poultry. British Veterinary Journal 1988;144:81-92.

Lequesne M, Malghem J, Dion E. The normal hip joint space: variations in width, shape, and architecture on 223 pelvic radiographs. Annals of the Rheumatic Diseases 2004;63(9):1145-1151.

Locsmándi L, Romvári R, Bogenfürst F, Szabó A, Molnár M, AndrássyBaka $\mathrm{G}$, et al. In vivo 3D evaluation of goose liver development by means of computer tomography. Animal Research 2004;54(2):135-145.

Murawska D. Age-Related Changes in the Percentage Content of Edible and Non-Edible Components in Turkeys. Poultry Science 2013;92:255264.

Reilly SM. Locomotion in the quail (Coturnix japonica). The Kinematics of walking and increasing speed. Journal of Morphology 2000;243:173185.

Resende RO, Martins EN, Georg PC, Paiva E, Conti ACM, Santos Al, et al. Variance components for body weight in Japanese quails (Coturnix japonica). Revista Brasileira de Ciência Avícola 2005;7(1):23-25.

Roemer FW, Guermazi A. Osteoarthritis year in review 2014: imaging. Osteoarthritis and Cartilage 2014;22(12):2003-2012.

Romvári R, Petrási Z, Sütő Z, Szabó A, Garamvölgyi R, Andrássy G, et al. Non-invasive characterization of the turkey heart performance and its relationship to skeletal muscle volume. Poultry Science 2004;83:696700 .

Sipola P, Niemitukia LH, Hyttinen MM, Arokoski JP. Sample size for prospective studies of hip joint space width narrowing in osteoarthritis by the use of radiographs. Skeletal Radiology 2011;40(4):431-438.

Turmezei TD, Lomas DJ, Hopper MA, Poole KE. Severity mapping of the proximal femur: a new method for assessing hip osteoarthritis with computed tomography. Osteoarthritis Cartilage. 2014;22(10):14881498

Vahdati A, Walscharts S, Jonkers I, Garcia-Aznar JM, Vander Sloten J, van Lenthe $\mathrm{GH}$. Role of subject-specific musculoskeletal loading on the prediction of bone density distribution in the proximal femur. Journal of the Mechanical Behavior of Biomedical Materials 2014;244-252. 